\title{
Retail Deli Slicer Cleaning Frequency — Six Selected Sites, United States, 2012
}

\author{
Laura G. Brown, $\mathrm{PhD}^{1}$; E. Rickamer Hoover, $\mathrm{PhD}^{1}$; Danny Ripley ${ }^{2}$; Bailey Matis, $\mathrm{MPH}^{3}$; David Nicholas, $\mathrm{MPH}^{4}$; Nicole Hedeen, $\mathrm{MS}^{5}$; Brenda Faw ${ }^{6}$
}

Listeria monocytogenes (Listeria) causes the third highest number of foodborne illness deaths (an estimated 255) in the United States annually, after nontyphoidal Salmonella species and Toxoplasma gondii (1). Deli meats are a major source of listeriosis illnesses $(2,3)$, and meats sliced and packaged at retail delis are the major source of listeriosis illnesses attributed to deli meat (4). Mechanical slicers pose cross-contamination risks in delis and are an important source of Listeria crosscontamination $(5,6)$. Reducing Listeria contamination of sliced meats in delis will likely reduce Listeria illnesses and outbreaks (G). Good slicer cleaning practices can reduce this foodborne illness risk (7). CDC's Environmental Health Specialists Network (EHS-Net) studied how often retail deli slicers were fully cleaned (disassembled, cleaned, and sanitized) at the Food and Drug Administration (FDA) Food Code-specified minimum frequency of every 4 hours and examined deli and staff characteristics related to slicer cleaning frequency (8). Interviews with staff members in 298 randomly-selected delis in six EHS-Net sites showed that approximately half of delis fully cleaned their slicers less often than FDA's specified minimum frequency. Chain-owned delis and delis with more customers, more slicers, required manager food safety training, food safety-knowledgeable workers, written slicer-cleaning policies, and food safety-certified managers fully cleaned their slicers more frequently than did other types of delis, according to deli managers or workers. States and localities should require deli manager training and certification, as specified in the FDA Food Code. They should also consider encouraging or requiring delis to have written slicer-cleaning policies. Retail food industry leaders can also implement these prevention efforts to reduce risk in their establishments. Because independent and smaller delis had lower frequencies of slicer cleaning, prevention efforts should focus on these types of delis.

The FDA Food Code is a model food code offered for adoption by state and local governmental jurisdictions that regulate retail food safety (i.e., states and localities). It contains science-based guidance to improve food safety in retail food service establishments. Although not all states and localities have adopted the latest version of the Food Code (2013), FDA and CDC strongly encourage its adoption at all levels of government.* The FDA Food Code states that food contact surfaces, including slicers, should be cleaned and sanitized at

\footnotetext{
*Introduction to the 2013 Food Code. http://www.fda.gov/downloads/Food/ GuidanceRegulation/RetailFoodProtection/FoodCode/UCM374510.pdf.
}

least every 4 hours (4-602.11[C]) (8), and that food contact surfaces should be disassembled before cleaning and sanitizing (4-202.11[A][5]) (8). U.S. Department of Agriculture (USDA) guidance also recommends slicer disassembly before cleaning and sanitizing $(\circlearrowleft$ ). Knowledge about retail delis' cleaning practices is critical to developing effective interventions. EHS-Net, a collaborative program of CDC, FDA, USDA, and six EHS-Net-funded state and local health departments, ${ }^{\dagger}$ assessed how often deli slicers were fully cleaned (disassembled, cleaned, and sanitized) at the FDA-specified minimum frequency of every 4 hours. EHS-Net also assessed deli and staff characteristics related to slicer cleaning frequency.

Within each EHS-Net site, data collectors chose a convenient geographic area, based on reasonable travel distance, in which to survey delis by telephone to determine study eligibility and request study participation. A software program was then used to select a random sample of delis within in each of the site geographic areas. Delis eligible for the study had at least one slicer, prepared or served ready-to-eat foods (with a delay between purchase and consumption), and had staff members who could be interviewed in English. Data collectors assessed approximately 50 delis in each site. Data were collected during January-September 2012.

Data collectors interviewed deli managers about their characteristics, their deli's characteristics; and how often slicers were fully cleaned ("On average, how many times are food slicers fully cleaned [disassembled, cleaned, and sanitized] during a shift?"). Deli managers also completed a written, eight-item food safety knowledge survey. Data collectors interviewed food workers, away from the manager, about their characteristics and food safety knowledge, and how often each slicer was fully cleaned ("How often do you break down, clean, then sanitize this slicer?”). Simple and multiple logistic regression models were used to examine associations between deli, manager, and worker characteristics and slicer-cleaning frequencies. The cut-off for variable inclusion in the multiple regression models was $p \leq 0.10$.

Among 691 managers of eligible delis who were contacted, 298 (43\%) agreed to be interviewed. In 294 (98.7\%) participating delis, data collectors were also able to interview a worker. The majority of delis were chains $(55.0 \%)$ and had $1-2$ slicers (56.8\%) (Table 1).

\footnotetext{
$\dagger^{\dagger}$ California Department of Public Health, Minnesota State Department of Health, New York State Department of Health, New York City Department of Health and Mental Hygiene, State of Rhode Island Department of Health, and Tennessee State Department of Health.
} 
TABLE 1. Reported slicer cleaning frequency, and deli, manager, and worker characteristics, obtained from manager interviews and surveys, and worker interviews* - six EHS-Net sites, ${ }^{\dagger} 2012$

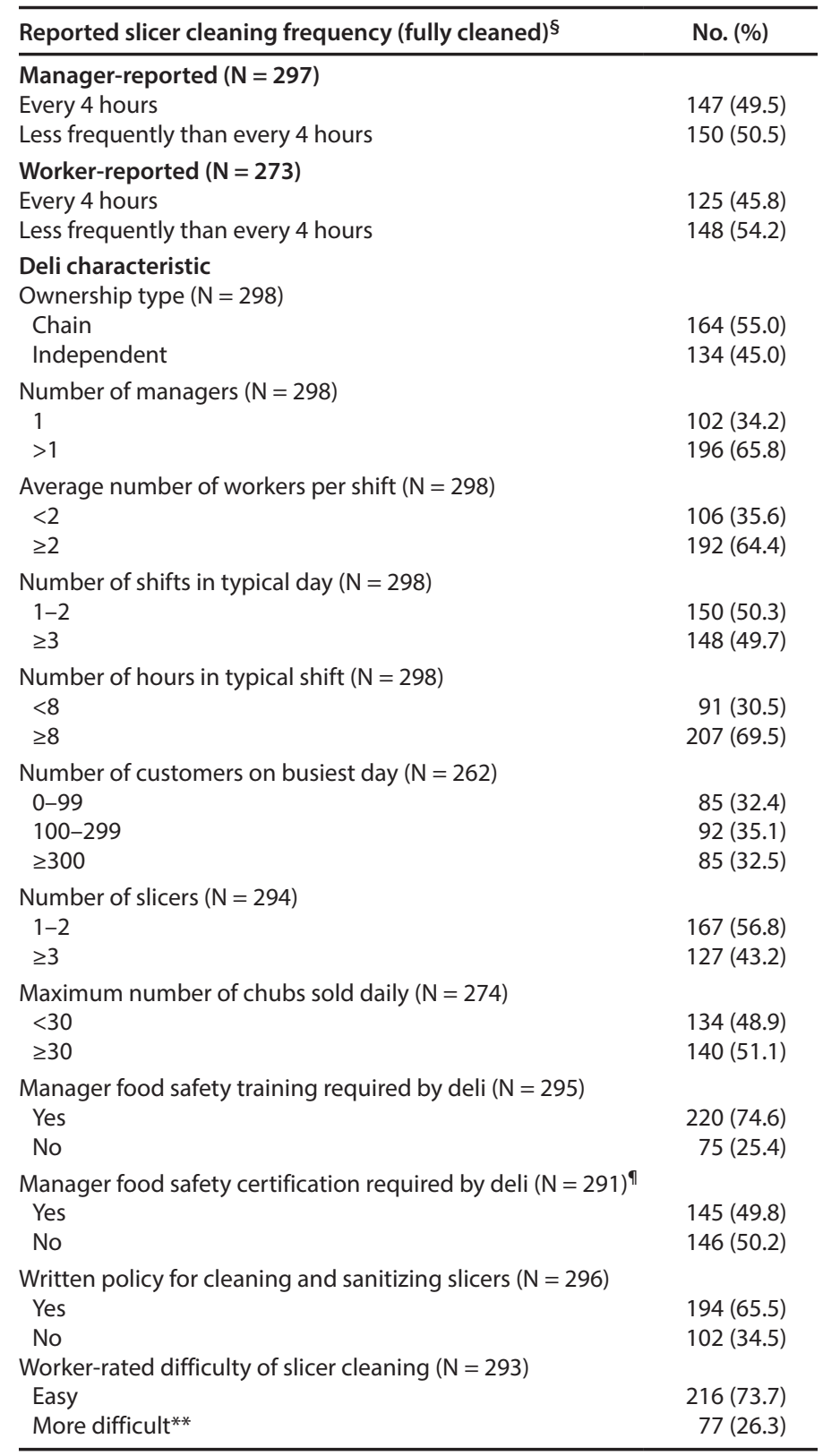

Half of managers (49.5\%) said that slicers were fully cleaned at least every 4 hours (Table 1). The remaining managers said that slicers were fully cleaned less frequently. Workers reported that $63.0 \%$ (393 of 624) of slicers were fully cleaned at least every 4 hours. Deli-level aggregation of these worker-reported data indicated that in $45.8 \%$ of delis, all slicers were fully cleaned at least every 4 hours (Table 1 ). In the remaining delis, at least one slicer was fully cleaned less frequently. Managers and workers agreed on cleaning frequency in $79.0 \%$ of delis (215 of $279, \mathrm{r}=0.587, \mathrm{p}<0.001)$.
TABLE 1. (Continued) Reported slicer cleaning frequency, and deli, manager, and worker characteristics, obtained from manager interviews and surveys, and worker interviews* - six EHS-Net sites, ${ }^{\dagger} 2012$

\begin{tabular}{|c|c|}
\hline Reported slicer cleaning frequency (fully cleaned) ${ }^{\S}$ & No. $(\%)$ \\
\hline \multicolumn{2}{|l|}{ Manager characteristic } \\
\hline$\leq 10$ & 77 (25.8) \\
\hline$>10-15$ & $50(16.8)$ \\
\hline$>15$ & $171(57.4)$ \\
\hline \multicolumn{2}{|l|}{ Experience as manager in current deli (yrs) $(\mathrm{N}=298)$} \\
\hline$\leq 5$ & $156(52.3)$ \\
\hline$>5$ & $142(47.7)$ \\
\hline \multicolumn{2}{|l|}{ Ever food safety certified $(N=297)^{q}$} \\
\hline Yes & $203(68.4)$ \\
\hline No & $94(31.6)$ \\
\hline \multicolumn{2}{|l|}{ Currently food safety certified $(N=297)^{\uparrow}$} \\
\hline Yes & $164(55.2)$ \\
\hline No & $133(44.8)$ \\
\hline \multicolumn{2}{|l|}{ Food safety knowledge assessment $(\mathrm{N}=298)$} \\
\hline$<75 \%$ correct & $97(32.6)$ \\
\hline$\geq 75 \%$ correct & $201(67.4)$ \\
\hline \multicolumn{2}{|l|}{ Worker characteristic } \\
\hline \multicolumn{2}{|l|}{ Experience in retail food industry (yrs) $(\mathrm{N}=293)$} \\
\hline$\leq 10$ & $163(55.6)$ \\
\hline$>10-15$ & $57(19.5)$ \\
\hline$>15$ & $73(24.9)$ \\
\hline \multicolumn{2}{|l|}{ Experience in current deli (yrs) $(\mathrm{N}=294)$} \\
\hline$\leq 5$ & $190(64.6)$ \\
\hline$>5$ & $104(35.4)$ \\
\hline \multicolumn{2}{|l|}{ Food safety knowledge assessment $(\mathrm{N}=294)$} \\
\hline$<100 \%$ correct & $157(53.4)$ \\
\hline $100 \%$ correct & $137(46.6)$ \\
\hline $\begin{array}{l}\text { Abbreviation: EHS-Net }=\text { Environmental Health Speci } \\
\text { * Numbers vary because of missing data. } \\
\text { †California, Minnesota, New York, New York City, Rhoc } \\
\text { § Disassembled, cleaned, and sanitized. } \\
\text { "Certification defined as having taken and passed a f } \\
\text { issued a certificate. } \\
\text { * Somewhat easy, neither easy nor difficult to clean, som }\end{array}$ & $\begin{array}{l}\text { work. } \\
\text { and Tennesse } \\
\text { test and bee }\end{array}$ \\
\hline
\end{tabular}

Simple regression models showed that the characteristics of deli chain ownership, a higher average number of workers per shift, more shifts per day, more customers served on the busiest day, more slicers, more chubs (plastic tubes of meat) sold daily, deli-required manager food safety training, a written policy on slicer cleaning, manager certification (current or ever), and manager and worker food safety knowledge were significantly associated with both managers and workers indicating that their slicers were fully cleaned at least every 4 hours (Table 2). Worker rating of deli slicers as easy to clean was significantly associated with managers indicating that slicers were fully cleaned at least every 4 hours. Deli-required manager food safety certification and more worker experience in the deli were significantly associated with workers indicating that slicers were fully cleaned at least every 4 hours. 
TABLE 2. Simple logistic regression models of deli, manager, and worker characteristics associated with managers and workers reporting that slicers in their delis are fully cleaned* at the FDA-specified frequency (at least every 4 hours) - six EHS-Net Sites, ${ }^{\dagger} 2012$

\begin{tabular}{|c|c|c|c|c|c|c|c|}
\hline \multirow[b]{2}{*}{ Characteristic } & \multirow[b]{2}{*}{ Comparison§ } & \multicolumn{3}{|c|}{$\begin{array}{l}\text { Managers reported that slicers are fully } \\
\text { cleaned at least every } 4 \text { hours }\end{array}$} & \multicolumn{3}{|c|}{$\begin{array}{l}\text { Workers reported that slicers are fully cleanec } \\
\text { at least every } 4 \text { hours }\end{array}$} \\
\hline & & No.? & OR $(95 \% \mathrm{Cl})$ & $\begin{array}{c}p \text {-value } \\
\text { for comparisons }\end{array}$ & No.q & OR $(95 \% \mathrm{Cl})$ & $\begin{array}{c}p \text {-value } \\
\text { for comparisons }\end{array}$ \\
\hline \multicolumn{8}{|l|}{ Deli characteristic } \\
\hline Ownership type & $\begin{array}{l}\text { Chain versus } \\
\text { independent }\end{array}$ & 293 & $4.41(2.36,8.25)$ & $\leq 0.001$ & 272 & $5.21(2.50,10.85)$ & $<0.001$ \\
\hline Number of managers & 1 versus $>1$ & 293 & $0.74(0.41,1.33)$ & 0.310 & 272 & $1.02(0.53,1.94)$ & 0.960 \\
\hline Average number of workers per shift & $\geq 2$ versus $<2$ & 293 & $3.51(1.85,6.65)$ & 0.003 & 272 & $3.48(1.63,7.40)$ & 0.007 \\
\hline Number of shifts in a typical day & $\geq 3$ versus 1 or 2 & 293 & $2.92(1.60,5.32)$ & $<0.001$ & 272 & $2.63(1.37,5.02)$ & 0.004 \\
\hline Number of hours in a typical shift & $<8$ versus $\geq 8$ & 293 & $1.06(0.59,1.93)$ & 0.841 & 293 & $1.52(0.80,2.87)$ & 0.198 \\
\hline \multirow[t]{2}{*}{ Number of customers on busiest day** } & $\begin{array}{r}100-299 \text { versus } \\
0-99\end{array}$ & 257 & $5.84(2.59,13.21)$ & $<0.001$ & 236 & $8.71(3.12,24.33)$ & $<0.001$ \\
\hline & $\geq 300$ versus $0-99$ & 257 & $5.05(2.29,11.13)$ & $<0.001$ & 236 & $6.75(2.49,18.26)$ & $<0.001$ \\
\hline Number of slicers & $\geq 3$ versus 1 or 2 & 293 & $3.23(1.77,5.91)$ & $<0.001$ & 272 & $4.47(2.33,8.55)$ & $<0.001$ \\
\hline Maximum number of chubs sold daily & $\geq 30$ versus $<30$ & 269 & $2.68(1.47,4.91)$ & 0.001 & 250 & $3.66(1.86,7.20)$ & 0.001 \\
\hline $\begin{array}{l}\text { Manager food safety training required } \\
\text { by deli }\end{array}$ & yes versus no & 291 & $2.29(1.08,4.85)$ & 0.032 & 270 & $4.55(1.69,12.46)$ & 0.003 \\
\hline $\begin{array}{l}\text { Manager food safety certification required } \\
\text { by deli }^{\dagger \dagger}\end{array}$ & yes versus no & 286 & $1.48(0.81,2.69)$ & 0.200 & 270 & $2.82(1.42,5.59)$ & 0.003 \\
\hline $\begin{array}{l}\text { Written policy for slicer cleaning and } \\
\text { sanitizing }\end{array}$ & yes versus no & 291 & $4.46(2.21,9.01)$ & $<0.001$ & 271 & $6.02(2.59,14.00)$ & $<0.001$ \\
\hline Worker-rated difficulty of slicer cleaning & $\begin{array}{r}\text { Easy versus more } \\
\text { difficult }{ }^{\S \S}\end{array}$ & 292 & $1.98(1.02,3.82)$ & 0.043 & 271 & $1.54(0.77,3.10)$ & 0.223 \\
\hline \multicolumn{8}{|l|}{ Manager characteristic } \\
\hline \multirow{2}{*}{ Experience in retail food industry (yrs) } & $\leq 10$ versus $\geq 15$ & 293 & $0.88(0.46,1.69)$ & 0.532 & 272 & $0.82(0.39,1.70)$ & 0.600 \\
\hline & $>10-15$ versus $\geq 15$ & 293 & $1.18(0.54,2.59)$ & 0.554 & 272 & $1.00(0.43,2.33)$ & 0.808 \\
\hline Experience as manager in current deli (yrs) & $\leq 5$ versus $>5$ & 293 & $1.51(0.87,2.63)$ & 0.140 & 272 & $1.22(0.67,2.24)$ & 0.517 \\
\hline Ever food safety certified & yes versus no & 292 & $1.72(0.90,3.27)$ & 0.099 & 271 & $2.29(1.12,4.72)$ & 0.024 \\
\hline Currently food safety certified & yes versus no & 292 & $2.06(1.08,3.93)$ & 0.028 & 271 & $1.74(0.97,3.12)$ & 0.063 \\
\hline Food safety knowledge assessment & $\begin{array}{r}\geq 75 \% \text { correct versus } \\
<75 \% \text { correct }\end{array}$ & 293 & $3.28(1.65,6.53)$ & 0.001 & 272 & $3.15(1.42,7.01)$ & 0.005 \\
\hline \multicolumn{8}{|l|}{ Worker characteristic } \\
\hline \multirow[t]{2}{*}{ Experience in retail food industry (yrs) ${ }^{* * *}$} & $\leq 10$ versus $>15$ & 293 & $1.47(0.76,2.88)$ & 0.209 & 272 & $0.87(0.41,1.78)$ & 0.287 \\
\hline & $>10-15$ versus $>15$ & 293 & $1.04(0.45,2.40)$ & 0.675 & 272 & $1.48(0.59,3.69)$ & 0.251 \\
\hline Experience in current deli (yrs) & $\leq 5$ versus $>5$ & 293 & $0.99(0.56,1.75)$ & 0.962 & 272 & $0.51(0.27,0.97)$ & 0.039 \\
\hline Food safety knowledge assessment & $\begin{array}{r}100 \% \text { correct versus } \\
<100 \% \text { correct }\end{array}$ & 293 & $2.53(1.41,4.52)$ & 0.002 & 272 & $1.93(1.03,3.62)$ & 0.041 \\
\hline
\end{tabular}

Abbreviations: $\mathrm{Cl}$ = confidence interval; EHS-Net = Environmental Health Specialists Network; FDA = Food and Drug Administration; OR = odds ratio.

* Disassembled, cleaned, and sanitized.

† California, Minnesota, New York, New York City, Rhode Island, and Tennessee.

$\S$ The reference level is the second category listed. Thus, the odds ratio is for the first category listed compared to the second category listed.

" Numbers vary because of missing data.

** P-values for the overall ORs: $p=0.001$ and $p<0.001$ for the manager and worker models, respectively.

${ }^{+\dagger}$ Certification defined as having taken and passed a food safety test and been issued a certificate.

$\S \S$ Somewhat easy, neither easy nor difficult to clean, somewhat difficult, or difficult.

Iी P-values for the overall ORs: $p=0.803$ and $p=0.856$ for the manager and worker models, respectively.

*** P-values for the overall ORs: $p=0.441$ and $p=0.445$ for the manager and worker models, respectively.

A multiple regression model showed that deli chain ownership, more customers served on the busiest day, and worker food safety knowledge were significantly associated with managers indicating that slicers were fully cleaned at least every 4 hours. A second multiple regression model showed that deli chain ownership, more customers served on the busiest day, more slicers, more chubs sold daily, deli-required manager food safety training, and more worker experience in the deli were significantly associated with workers indicating that slicers were fully cleaned at least every 4 hours. (Table 3).

\section{Discussion}

These analyses indicate that many delis have insufficient slicercleaning frequency, which could lead to cross-contamination of deli meats with Listeria and other pathogens. In at least half of delis studied, managers and workers reported that slicers were not fully cleaned at the FDA-specified minimum frequency of every 4 hours.

Multiple regression findings indicate that chain delis reported more frequent slicer cleaning than did independent delis, and delis with more slicers, serving more customers, and selling more 
TABLE 3. Multiple logistic regression models* of deli, manager, and worker characteristics associated with managers and workers indicating that in their deli, slicers are fully cleaned ${ }^{\dagger}$ at the FDA-specified frequency (at least every four hours) — six EHS-Net sites, ${ }^{\S} 2012$

\begin{tabular}{|c|c|c|c|}
\hline Characteristic & Comparison? & OR $(95 \% \mathrm{Cl})$ & p-value for comparisons \\
\hline \multicolumn{4}{|l|}{ Manager model $(\mathrm{N}=257)$} \\
\hline Ownership type & Chain versus independent & $2.78(1.30,5.96)$ & 0.008 \\
\hline \multirow{2}{*}{ Number of customers on busiest day } & $100-299$ versus $0-99$ & $4.32(1.85,10.11)$ & $<0.001$ \\
\hline & $\geq 300$ versus $0-99$ & $2.71(1.10,6.70)$ & 0.031 \\
\hline Worker food safety knowledge assessment & $100 \%$ correct versus $<100 \%$ correct & $2.15(1.11,4.17)$ & 0.023 \\
\hline \multicolumn{4}{|l|}{ Worker model $(\mathrm{N}=222)$} \\
\hline Ownership type & Chain versus independent & $4.65(1.52,14.25)$ & 0.007 \\
\hline \multirow{2}{*}{ Number of customers on busiest day ${ }^{\dagger \dagger}$} & $100-299$ versus $0-99$ & $3.42(0.96,12.16)$ & 0.057 \\
\hline & $\geq 300$ versus $0-99$ & $0.76(0.18,3.26)$ & 0.713 \\
\hline Number of slicers & $\geq 3$ versus 1 or 2 & $2.42(0.92,6.39)$ & 0.074 \\
\hline Maximum number of chubs sold daily & $\geq 30$ versus $<30$ & $2.36(0.85,6.54)$ & 0.098 \\
\hline Manager food safety training required by deli & yes versus no & $4.30(0.93,19.87)$ & 0.062 \\
\hline Worker experience in current deli (yrs) & $\leq 5$ versus $>5$ & $0.45(0.20,1.04)$ & 0.061 \\
\hline
\end{tabular}

Abbreviations: $\mathrm{Cl}=$ confidence interval; $\mathrm{EHS}-\mathrm{Net}=$ Environmental Health Specialists Network; $\mathrm{FDA}=$ Food and Drug Administration; $\mathrm{OR}=$ odds ratio.

* Manager overall model $\left(X^{2}=36.54\right.$, degrees of freedom $\left.(d f)=4, p<0.001\right)$ created using forward selection criteria of $p \leq 0.10$. Worker overall model $\left(X^{2}=54.96\right.$, $\mathrm{df}=7, \mathrm{p}<0.001$ ) created using forward selection criteria of $\mathrm{p} \leq 0.10$. When employing a forward selection procedure, all predictors of interest (i.e., deli, manager, and worker characteristics in this study) are systematically individually tested to see which is most significant within the model. Once identified, this predictor is added to the model and the remaining predictors are retested. This procedure is repeated until all remaining predictors fail to meet the entrance criteria. Each final model presented above simultaneously included all variables shown in the table. Individual inclusion steps are not presented.

† Disassembled, cleaned, and sanitized.

$\S$ California, Minnesota, New York, New York City, Rhode Island, and Tennessee.

n The reference level is the second category listed. Thus, the odds ratio is for the first category listed compared to the second category listed.

** P-value for the overall OR: $p=0.003$.

t† $\mathrm{P}$-value for the overall OR: $\mathrm{p}=0.006$.

chubs daily reported more frequent slicer cleaning than did delis with fewer slicers, serving fewer customers, or selling fewer chubs daily. These characteristics are likely indicators of deli size, and these data are consistent with other findings suggesting that both chain and larger establishments' food safety practices tend to be better than those of independent and smaller establishments $(9,10)$. Compared with both independent and smaller delis, chain and larger delis might have more resources, more or better trained staff, or more standardized cleaning procedures.

The association of required manager food safety training and certification with more frequent reported slicer-cleaning is consistent with other findings indicating that training and certification are important in retail food safety $(9,10)$, and highlights the important role that management can play in food safety. The finding that delis with workers with more food safety knowledge and experience had more frequent reported slicer cleaning suggests that workers also play an important role in food safety.

Simple logistic regression findings suggest other characteristics that might improve cleaning frequencies. Written slicercleaning policies and worker ratings of slicers as being easy to clean were both associated with more frequent reported cleaning, suggesting that workplace policies and slicer design can affect cleaning frequency. Finally, delis with a food safetycertified manager had better reported cleaning frequencies, again pointing to the importance of training and certification.

Because slicer-cleaning frequency and disassembly guidance are presented separately from each other in the FDA Food
Code, some deli managers might be unaware that cleaning should include disassembly, and might clean and sanitize slicers without disassembling them. It is also possible that some slicers included in this study, especially newer ones, do not need to be disassembled to be fully cleaned.

The findings in this study are subject to at least three limitations. First, the interview data might be affected by social desirability bias, which might have resulted in overreporting of cleaning frequency. Second, because interviewed workers were selected by managers, and not at random, worker data might not represent all workers. Finally, because the data were collected from English-speaking staff members only, they might not reflect practices in delis with no English-speaking staff. It is also important to note that the data from this study do not allow causal inferences about relationships between characteristics and cleaning frequency nor do they link slicer cleaning frequency with foodborne illness.

States and localities should require deli manager training and certification, as specified in the FDA Food Code. They should also consider providing education on the topics of slicer-cleaning frequency and the importance of slicer disassembly, and encouraging or requiring delis to have written slicer-cleaning policies. Retail food industry leaders can also implement these prevention efforts to reduce risk in their food establishments. Because frequencies of slicer cleaning were lower at independent and smaller delis, prevention efforts should focus on these types of establishments. 


\section{Summary}

What is already known about this topic?

Listeria monocytogenes (Listeria) causes the third highest number of foodborne illness deaths in the United States annually. Listeria contamination of sliced deli meats at retail locations contributes to Listeria illness and outbreaks. Mechanical slicers pose cross-contamination risks in retail delis and are an important source of Listeria cross-contamination. Good slicer cleaning practices can reduce this risk.

What is added by this report?

In approximately half of retail delis studied in six Environmental Health Specialists Network sites, slicers were fully disassembled, cleaned, and sanitized less frequently than the minimum 4 hours specified in the Food and Drug Administration (FDA) Food Code. Slicers were fully cleaned more frequently in chain delis, and in delis with more customers, more slicers, required manager food safety training, food safety-knowledgeable workers, written slicer cleaning policies, and food safety-certified managers than in delis in other categories. What are the implications for public health practice?

To help ensure that deli slicers are cleaned at least every 4 hours as a foodborne illness prevention measure, states and localities should require deli manager training and certification, as specified in the FDA Food Code. They should also consider encouraging or requiring delis to have written slicer-cleaning policies. Retail food industry leaders can also implement these prevention efforts to reduce risk in their food establishments. Because independent and smaller delis show lower frequencies of slicer cleaning, prevention efforts should focus on these types of delis.

\section{Acknowledgments}

Participating deli managers and workers; EHS-Net site staff members; Food and Drug Administration (FDA), U.S. Department of Agriculture; Brenda Le, Carol Selman, CDC; Denita Williams, FDA.

\footnotetext{
${ }^{1}$ Division of Emergency and Environmental Health Services, National Center for Environmental Health, CDC, ${ }^{2}$ Tennessee Department of Health, ${ }^{3} \mathrm{New}$ York City Department of Health and Mental Hygiene, ${ }^{4}$ New York State Department of Health, ${ }^{5}$ Minnesota Department of Health; ${ }^{6}$ California Department of Public Health.
}

Corresponding author: Laura G. Brown, lrgreen@cdc.gov, 770-488-4332.

\section{References}

1. Scallan E, Hoekstra RM, Angulo FJ, et al. Foodborne illness acquired in the United States-major pathogens. Emerg Infect Dis 2011;17:7-15. http://dx.doi.org/10.3201/eid1701.P11101

2. Batz MB, Hoffmann S, Morris JG Jr. Ranking the disease burden of 14 pathogens in food sources in the United States using attribution data from outbreak investigations and expert elicitation. J Food Prot 2012;75:1278-91. http://dx.doi.org/10.4315/0362-028X.JFP-11-418

3. Cartwright EJ, Jackson KA, Johnson SD, Graves LM, Silk BJ, Mahon BE. Listeriosis outbreaks and associated food vehicles, United States, 1998-2008. Emerg Infect Dis 2013;19:1-9. http://dx.doi.org/10.3201/ eid 1901.120393

4. US Department of Agriculture. FSIS comparative risk assessment for Listeria monocytogenes in ready-to-eat meats and poultry deli meats. Washington, DC: US Department of Agriculture; 2010. http://www.fsis. usda.gov/wps/wcm/connect/c2ac97d0-399e-4c4a-a2bc-d338c2e201b3/ Comparative_RA_Lm_Report_May2010.pdf?MOD=AJPERES

5. US Department of Agriculture. Interagency risk assessment: Listeria monocytogenes in retail delicatessens. Washington, DC: US Department of Agriculture; 2013. http://www.fsis.usda.gov/wps/wcm/connect/ c0c6dfbc-ad83-47c1-bcb8-8db6583f762b/Lm-Retail-Technical-Report. pdf?MOD=AJPERES

6. US Department of Agriculture. FSIS best practices guidance for controlling Listeria monocytogenes $(\mathrm{Lm})$ in retail delicatessens. Washington, DC: US Department of Agriculture; 2015. http:// www.fsis.usda.gov/wps/wcm/connect/29d51258-0651-469b-99b8e986baee8a54/Controlling-LM-Delicatessens.pdf?MOD=AJPERES

7. Hoelzer K, Pouillot R, Gallagher D, Silverman MB, Kause J, Dennis S. Estimation of Listeria monocytogenes transfer coefficients and efficacy of bacterial removal through cleaning and sanitation. Int J Food Microbiol 2012;157:267-77. http://dx.doi.org/10.1016/j. ijfoodmicro.2012.05.019

8. Food and Drug Administration. Food and Drug Administration Food Code. Chapter 4. equipment, utensils, and linens. Silver Springs, MD: US Department of Health and Human Services, Food and Drug Administration; 2013. http://www.fda.gov/downloads/Food/ GuidanceRegulation/RetailFoodProtection/FoodCode/UCM374510.pdf

9. Bogard AK, Fuller CC, Radke V, Selman CA, Smith KE. Ground beef handling and cooking practices in restaurants in eight States. J Food Prot 2013;76:2132-40. http://dx.doi.org/10.4315/0362-028X.JFP-13-126

10. Brown LG. EHS-Net restaurant food safety studies: what have we learned? J Environ Health 2013;75:44-5. 